\title{
A construção de saberes matemáticos entre jovens e adultos do Morro de São Carlos*
}

\author{
Maria Cecilia de Castello Branco Fantinato \\ Universidade Federal Fluminense, Faculdade de Educação
}

\section{Introdução}

Propostas educacionais voltadas para a clientela jovem e adulta costumam defender que "o ponto de partida para a aquisição dos conteúdos matemáticos deve ser os conhecimentos prévios dos educandos" (Ribeiro, 1997, p. 100). Mas a efetivação de tal premissa não parece ser tarefa simples e levanta algumas interrogações. O que seriam "conhecimentos prévios" de jovens e adultos? Não haveria uma grande diversidade entre os mesmos, de acordo com grupos culturais, experiências profissionais, níveis de escolaridade anterior, entre outros fatores?

Em sua grande maioria, as propostas nessa área não têm levado em consideração a especificidade dessa clientela quanto à faixa etária, experiências profissionais e cotidianas, e formas de aprendizagem. Como diz Machado (1999, p. 1):

* Versão revista e ampliada de trabalho apresentado no Grupo de Trabalho Educação de Pessoas Jovens e Adultas, na 26a Reunião Anual da ANPEd, realizada em Poços de Caldas, MG, de 5 a 8 de outubro de 2003.
A falta de conhecimento dos fatos ou a opção política por desconsiderá-los acaba por fazer com que a EJA [Educação de Jovens e Adultos] esteja permanentemente "reinventando a roda", ou fortalecendo características indesejáveis como descontinuidade, oportunismo e baixa qualidade.

Os jovens e adultos analfabetos historicamente têm sido caracterizados, por políticas educacionais a eles destinadas, em sentido negativo, como sujeitos "analfabetos", "não-crianças", "não-escolarizados" (Oliveira, 1999). Existia portanto uma demanda de estudos que ajudassem a caracterizar o educando jovem e adulto no sentido de sua positividade, respondendo a perguntas do tipo: quem ele é, o que faz, como vive, o que sabe, o que pensa, como se pensa, o que aprende na escola, o que o faz voltar à escola.

Especificamente em relação ao campo da educação matemática, havia uma contradição, já apontada por muitas pesquisas, entre o sucesso no desempenho de adultos em situações da vida cotidiana que envolvem habilidades matemáticas, como na administração do orçamento doméstico ou no exercício profissional, e algumas dificuldades apresentadas na aprendizagem 
da linguagem matemática formal (Carraher, Carraher \& Schliemann, 1989; Carvalho, 1995, 1997). Tais estudos já indicavam também diferenças entre esses dois tipos de conhecimento matemático, por exemplo, quanto à forma, uns predominantemente baseados no cálculo mental, outros com o uso da linguagem matemática escrita como principal ferramenta. Mas ainda havia necessidade de melhor compreensão desse distanciamento.

Desenvolvendo inicialmente uma pesquisa exploratória em uma escola supletiva noturna de nível fundamental, pude constatar que supostos erros dos educandos jovens e adultos, em tarefas como o treino das técnicas operatórias, indicavam pistas de como eles pareciam estar raciocinando matematicamente. Um exemplo significativo é o de uma cozinheira, que aparentemente não estava conseguindo relacionar a palavra dúzia à quantidade doze, mas pôde, automaticamente, calcular mentalmente o valor de seis dúzias como equivalente a 72 , quando à palavra dúzia foi acrescentada outra, ovos, que forneceu um significado prático, próximo de sua vivência profissional, ao cálculo mais abstrato que lhe fora solicitado.

Situações como essa apontavam para uma vinculação do contexto sociocultural com as produções desses alunos. Tal pesquisa exploratória, desenvolvida exclusivamente no ambiente escolar, apontou também para a necessidade de estudos sobre os conhecimentos matemáticos informais de jovens e adultos em contextos não escolares, entre outros motivos porque a instituição formal de ensino não parecia ser o espaço mais adequado para a manifestação desses saberes. ${ }^{1}$

Procurando avançar na compreensão das formas próprias de conhecimento matemático construídas por

1 Um exemplo da falta de espaço concedida pela escola para as formas específicas dos saberes matemáticos desses alunos está na fala de uma aluna, recolhida durante a pesquisa exploratória, referindo-se a seus colegas do curso supletivo: "Eles dizem que não fazem de cabeça, mas fazem”. Provavelmente estariam negando o uso que faziam do cálculo mental na escola, por acharem que aquele tipo de procedimento não seria o mais escolar. jovens e adultos trabalhadores em contextos de vida cotidiana, elaborei meu projeto de pesquisa de doutorado buscando responder às seguintes questões iniciais:

a) Que tipos de conhecimento matemático são construídos por alunos jovens e adultos da classe trabalhadora, em seus contextos de vida social, profissional ou doméstica?

b) Que relações esses conhecimentos, produzidos em contextos extra-escolares, possuem com os conhecimentos matemáticos escolares?

c) Como uma melhor compreensão dos diferentes tipos de conhecimento matemático, construídos por jovens e adultos do ensino fundamental, pode contribuir para práticas educativas voltadas para essa clientela?

A fundamentação teórica da referida pesquisa baseou-se nas contribuições de duas áreas: a educação matemática de jovens e adultos e a etnomatemática.

\section{Educação matemática de jovens e adultos}

Em primeiro lugar, analisei a contribuição de autores brasileiros em educação de jovens e adultos, particularmente daqueles relacionados à aprendizagem e ao ensino da matemática. Consultei também algumas publicações internacionais recentes sobre o tema. Construí três eixos de análise, procurando classificar a produção na área de acordo com as metas prioritárias dos estudos/pesquisas/propostas em questão.

Para um primeiro grupo, a educação matemática de jovens e adultos seria um instrumento de conscientização política. Tendo sido o educando adulto um excluído da escola regular, e tendo o ensino da matemática formal contribuído parcialmente nesse processo de exclusão, uma das metas da educação de jovens e adultos passaria a ser precisamente a reversão dessa situação. Nas palavras de Paulo Freire: ${ }^{2}$

\footnotetext{
2 Em entrevista concedida em 1996 a Ubiratan D’Ambrósio
} e Maria do Carmo S. Domite, cuja transcrição está disponível no site <http://vello.sites.uol.com.br/entrevista.htm>. 
Eu acho que no momento em que você traduz a naturalidade da matemática como uma condição de estar no mundo, você trabalha contra um certo elitismo dos matemáticos [...] Você democratiza a possibilidade da naturalidade da matemática: isso é cidadania.

Para autores como Garcia (1985) e Duarte (1985), a aprendizagem do código escrito da língua materna e do código matemático formal contribui para o desvelamento da situação de oprimido do educando jovem/adulto, para o desenvolvimento de sua conscientização política. Newton Duarte vê uma dimensão política intrínseca na forma como é socializado o conteúdo matemático, podendo o ensino da matemática contribuir, ou não, para as transformações sociais. Sua proposta foi bastante inovadora na época, uma das primeiras adaptações das idéias de Paulo Freire para a educação matemática. Poderia ser hoje criticado por um certo evolucionismo, porque o conhecimento matemático dos alunos é visto por ele como uma etapa inicial, mais primitiva, portanto, de uma escala evolutiva que leva até o estágio final do conhecimento matemático formal.

Em trabalhos mais recentes, a perspectiva evolucionista do conhecimento matemático já não aparece, embora permaneça a preocupação com a dimensão política da educação matemática de jovens e adultos. Gelsa Knijnik desenvolve há anos um trabalho de ensino e pesquisa junto ao Movimento dos Trabalhadores Rurais Sem Terra (MST) e de formação de professores para os projetos de educação de adultos do movimento. Seu trabalho procura integrar os conhecimentos matemáticos desenvolvidos por esses jovens e adultos como fruto de suas experiências de trabalhadores do campo (como formas próprias de cálculo da área a ser plantada), com a matemática acadêmica. A aprendizagem da "matemática dos livros"3 é vista como essencial para instrumentalizar

3 Termo utilizado por alunos do curso magistério de férias do Departamento de Educação Rural da Fundação para o Desenvolvimento, Educação e Pesquisa da Região Celeiro, no trabalho esses homens e mulheres na sua luta pela posse da terra e cultivo da mesma. Nessa perspectiva de educação de jovens e adultos, a aprendizagem da matemática é política, porque atende às demandas de um grupo social na defesa de seus interesses de produtores agrícolas; é política, também, porque estabelece um diálogo entre os diferentes tipos de conhecimento matemático, considerando-se as relações de poder implícitas nesse confronto.

Alexandrina Monteiro (1998) é outra pesquisadora de educação matemática que lidou com trabalhadores rurais de um assentamento localizado no estado de São Paulo. A autora procura seguir a perspectiva da etnomatemática na sua proposta pedagógica, que exige uma

$$
\begin{aligned}
& \text { [...] postura de compromisso, não apenas com o saber insti- } \\
& \text { tucional ou local, mas um compromisso político, que busca } \\
& \text { no processo educacional um espaço para vozes selecionadas } \\
& \text { diante de um saber institucional dominante, que, ao se faze- } \\
& \text { rem presentes, possibilitem refletir e compreender diferen- } \\
& \text { tes práticas e procedimentos, como também, ao se apropria- } \\
& \text { rem de novos elementos, permitam aos grupos, até então ca- } \\
& \text { lados, eleger qual procedimento ou destino a seguir. (p. 114) }
\end{aligned}
$$

Essas propostas em educação de jovens e adultos possuem, portanto, uma perspectiva política: "coerentes com o propósito de contribuir para a conquista de melhores e mais inclusivas condições de cidadania para seus alunos e alunas" (Fonseca, 2002, p. 85).

Um segundo grupo de estudos e pesquisas associa a educação matemática de jovens e adultos a uma instrumentação para o mercado de trabalho, cada vez mais exigente, das sociedades urbanas e industriais. Autores dessa linha estão basicamente preocupados com a requalificação, com o domínio de linguagens tecnológicas por parte dos educandos, e com o papel da educação matemática na consecução desse objetivo. Defendem, por exemplo, propostas de ensino com

desenvolvido por Knijnik em Braga, Rio Grande do Sul, em 1992 (Knijnik, 1996). 
o uso da calculadora (Lopes, 1997) e do computador (Singh, 2002).

Em alguns textos estrangeiros analisados, aparece o conceito de numeracia, ${ }^{4}$ definido por Iddo Gal (2000) como:

[...] um agregado de habilidades, conhecimentos, crenças, disposições, hábitos mentais, capacidades comunicativas e habilidades de resolução de problemas, que os indivíduos necessitam de maneira a se engajarem autonomamente e administrarem efetivamente situações de numeracia, que envolvem números, informação quantitativa ou quantificável, ou informação visual ou textual baseada em idéias matemáticas ou que tenha elementos matemáticos embutidos.

(p. 12, tradução minha)

Este autor preocupa-se com a análise da numeracia necessária à vida adulta, e como pode ser ensinada. Enquadra-se nessa categoria porque o domínio das citadas habilidades matemáticas é apontado como meio de acesso, orientação e destreza para manter-se num mundo em rápidas e constantes mudanças. Outros autores chegam a incluir em sua definição uma perspectiva dinâmica, ao afirmar que a numeracia vista como aquele conjunto de habilidades e conhecimentos matemáticos que todos deveriam ter - "muda de acordo com o tempo e o espaço, juntamente com as mudanças sociais e o desenvolvimento tecnológico" (Lindenskov \& Wedege, 2001, p. 5, tradução minha).

Essa segunda linha de estudos e pesquisas, guardadas as diferenças existentes entre cada trabalho, apresenta a característica comum de valorização da escolaridade formal e da aprendizagem da linguagem matemática oficial como forma de tornar o jovem e adulto mais inserido na sociedade que o exclui de diversas maneiras. As palavras de Fonseca (2002), por exemplo, indicam claramente o porquê da opção da

4 Tradução da autora, do termo em inglês, numeracy. Outros autores utilizam também, em sentido análogo, o termo numeramento (Toledo, 2002). autora por uma proposta de educação escolar para jovens e adultos:

Naturalmente, alunos e alunas da EJA percebem-se pressionados pelas demandas do mercado de trabalho e pelos critérios de uma sociedade onde o saber letrado é altamente valorizado. Mas trazem em seu discurso não apenas as referências à necessidade: reafirmam o investimento na realização de um desejo e a consciência (em formação) da conquista de um direito. Diante de nós, educadores da EJA, e conosco, estarão, pois, mulheres e homens que precisam, que querem e que reivindicam a Escola. (p. 49)

De acordo com Oliveira (1999), o tema dos processos de construção de conhecimento do aluno adulto é ainda pouco explorado pelos pesquisadores. Todavia, existem estudos que procuram levar em conta as características dos modos de pensar e agir do adulto, do ponto de vista cognitivo e/ou cultural. Identifiquei assim uma terceira categoria de análise dos trabalhos em educação de jovens e adultos, voltada para os modos próprios de raciocínio matemático do educando.

Dentro dessa vertente, alguns trabalhos têm uma perspectiva mais psicológica. Carvalho (1995, 1997), estudando a interação entre "conhecimento matemático da prática" e o conhecimento escolar, é uma representante do grupo. Essa autora fala em diferenças entre um e outro tipo de conhecimento, em relação, por exemplo, ao referencial no qual se validam.

O conhecimento matemático da prática deve ser eficaz, deve "funcionar". Nem sempre a validação é pautada pela lógica dedutiva. As soluções estão impregnadas pelas condições circunstanciais nas quais o problema foi gerado. Além disso, os procedimentos adquiridos na prática não precisam ser genéricos, e nem é necessário explicá-los oralmente. (Carvalho, 1997, p. 13)

Outro exemplo dentro dessa linha mais influenciada pela psicologia é o estudo de Maria Elena Toledo (1997) sobre os registros matemáticos dos adultos. A autora procura relacionar os procedimentos próprios que um grupo de adultos do ensino fundamental de- 
senvolve para a resolução de matemáticas cotidianas, com as representações numéricas e gráficas ensinadas pela escola. $\mathrm{O}$ objetivo de sua pesquisa é "investigar o processo de transição entre a oralidade na resolução de problemas e suas representações numéricas e gráficas" (p. 36). Toledo constatou uma dificuldade entre os alunos jovens e adultos pesquisados, para a compreensão e interpretação dos signos, apesar de sua facilidade para a realização de cálculos matemáticos.

Apesar de serem propostas de estudo de formas próprias de conhecimento matemático do adulto, algumas das pesquisas relatadas acima (Carvalho, 1995; Toledo, 1997) voltam-se para a produção de conhecimento apenas no contexto escolar. Os conhecimentos matemáticos prévios do aluno jovem/adulto são levados em conta, mas numa perspectiva evolucionista explícita (no caso de Toledo), onde o ideal a ser atingido é o conhecimento matemático escolar, ou como objeto de comparação (no caso de Carvalho), onde a matemática escolar é visivelmente mais valorizada que outras manifestações do pensamento matemático.

Partindo de uma perspectiva mais antropológica, considerando os modos próprios de produção e sistematização de conhecimento matemático por adultos em contextos não-escolares, o trabalho de Helena Oliveira (2002) é um bom exemplo. Tendo trabalhado com integrantes do MST durante muitos anos, ela declara: "tenho aprendido muito sobre os modos de viver e trabalhar das populações rurais, assim como sobre seus modos particulares de medir terras" (p. 44). A partir do reconhecimento dessas práticas, ela desenvolveu um trabalho pedagógico com jovens e adultos vinculados ao MST, trazendo os saberes dos agricultores para a sala de aula, como as unidades de medida rurais: a braça, o hectare, o celamin, a quarta, o alqueire, entre outras.

No panorama internacional, podemos situar Mary Harris (2000) dentro dessa terceira categoria. Sua proposta parte do raciocínio matemático de adultos, especificamente das mulheres, desenvolvendo estudos que procuram integrar a matemática ao trabalho em atividades tradicionais como o tricô, a costura e a tecelagem. Discute a associação dessas atividades tra- dicionais ao universo feminino, e da negação da matemática que lhes é inerente. A origem dessa situação, segundo a autora, "reside em fatores sociais e históricos que efetivamente associaram ao gênero tanto a matemática como o trabalho das mulheres, definindo a matemática como um tema masculino e o trabalho com agulhas como o estereótipo do feminilidade" (p. 271). A contribuição de Harris é simultaneamente educativa e política, pois busca desenvolver a auto-estima de mulheres que têm sido consideradas incapazes de aprender matemática.

Minha pesquisa (Fantinato, 2003), sobre os conhecimentos matemáticos de jovens e adultos de uma favela carioca, situa-se dentro desse terceiro grupo, por sua perspectiva sociocultural no estudo dos processos de raciocínio desse grupo.

\section{Etnomatemática}

A diversidade de enfoques sobre a etnomatemática exige que seja esclarecida a perspectiva adotada em minha pesquisa. Farei isso ao analisar algumas questões conflituosas que se apresentam ao pesquisador etnomatemático, apresentando meu posicionamento ante esse debate.

As pesquisas da área de etnomatemática (mesmo que não tivessem esse título) estiveram, desde sua origem, envolvidas com as relações entre conhecimento e cultura. Tentativas frustradas de ensino da matemática formal em contextos culturais estranhos à civilização ocidental, de início analisadas como fruto da privação cultural ${ }^{5}$ desses grupos, levaram aos poucos à reconsideração das diferenças no desempenho dos

\footnotetext{
5 Termo utilizado por pesquisas, da década de 1960 sobre-
} tudo, que explicavam o fracasso escolar de alguns alunos atribuindo às suas culturas de origem um caráter de privação em relação às culturas de grupos dominantes da sociedade, mais próximas da cultura escolar. A medida adotada para sanar essas "deficiências culturais" foi chamada de educação compensatória, que se propunha, como indica o nome, a compensar esse déficit através de propostas educacionais. 
alunos, associadas a fatores culturais. O êxito desses alunos em atividades do cotidiano que envolviam conhecimentos matemáticos desafiava o insucesso deles em matemática escolar. Demonstram-no as pesquisas de Gay e Cole (1967) com alunos Kpellle, da Libéria e as de Carraher, Carraher e Schliemann (1989) com meninos feirantes, no Nordeste brasileiro. Os diversos grupos culturais passaram a serem vistos como possuidores de conhecimentos matemáticos que faziam sentido dentro de seu universo cultural, e eficientes na resolução de problemas colocados pelo contexto. A caracterização desses conhecimentos instigava pesquisadores de áreas variadas, todavia com pontos de congruência, como a matemática, a educação, a antropologia, a psicologia cognitiva, entre outros.

Os primeiros estudos etnomatemáticos voltaramse, portanto, para a investigação de uma matemática presente em contextos culturais diferentes do ambiente acadêmico ou escolar, nas práticas cotidianas dos grupos estudados. Segundo relação apresentada por Eduardo Sebastiani Ferreira (1997), baseada em Paulus Gerdes, alguns nomes indicam o caminho teórico dos cientistas, procurando conceituar essa nova linha de pesquisa. Cito aqui alguns: Zaslawsky em 1973 - sociomatemática; D’Ambrósio em 1982 - matemática espontânea; Posner em 1982 - matemática informal; Carraher em 1982 e Kane em 1987 - matemática oral; Gerdes em 1982 - matemática oprimida; Carraher em 1982, Gerdes em 1985 e Harris em 1987 matemática não-estandardizada; Gerdes em 1982 e 1985 - matemática escondida ou congelada; Mellin e Olsen em 1986 - matemática popular; Sebastiani em 1987 - matemática codificada no saber-fazer.

Tais sinônimos para a etnomatemática, originários de metáforas diferentes, apresentam no entanto um ponto em comum: todos são construídos com base na palavra matemática. A existência de uma categoria chamada matemática não é colocada em questão, como se fosse tido como natural encontrá-la em qualquer cultura, variando apenas a sua forma de aparecer (espontânea, informal, oral, não-estandardizada, codificada no saber-fazer), ou de não aparecer (matemática escondida, congelada). Estariam essas deno- minações supondo uma universalidade para a matemática? Caso o estivessem, a busca da universalidade de uma categoria criada no mundo ocidental não seria contraditória com os próprios princípios da etnomatemática, já que "a abordagem a distintas formas de conhecer é a essência do programa etnomatemática" (D’Ambrósio, 1996, p. 111)? Bill Barton (1995) analisa essa contradição, dizendo:

Um dos problemas dos escritos em etnomatemática é que eles têm tentado ser universais em suas definições. E ainda, este tipo de tentativa contradiz a intenção da etnomatemática com relação à matemática. Parte do propósito da etnomatemática consiste em desafiar a natureza universal da matemática e em expor diferentes concepções matemáticas. Se este propósito for alcançado, então a etnomatemática também fica delimitada a um conceito particular de matemática. Logo, uma definição universal não é possível. (p. 216, tradução minha)

Alan Bishop (1988) tenta uma solução ao propor a universalidade de seis atividades matemáticas em todas as culturas: contar, medir, localizar, desenhar, jogar e explicar. Ele explica:

\footnotetext{
[...] não se pode nunca estabelecer a universalidade do fenômeno, apenas se está escolhendo descrever um conjunto muito extenso de semelhanças de uma certa maneira. No âmbito desse contexto de significado, a ser compreendido, continuarei a usar o termo "universal" para caracterizar as seis atividades que acabo de descrever.

Se elas são universais, e eu tenho argumentado com sucesso que elas são atividades significativas para o desenvolvimento dos aspectos matemáticos da cultura, logo o corolário deve ser que todas as culturas desenvolvem matemática de que matemática é um fenômeno pan-cultural. (p. 55, tradução minha)
}

Defende o autor, no entanto, a idéia de que existem diferentes matemáticas e não apenas uma matemática, e que a matemática (enquanto disciplina internacional assim conhecida) é o resultado do crescimento de uma linha específica de conhecimento, que foi cul- 
tivada por certos grupos culturais até chegar à sua forma atual. Bishop foi alvo de muitas críticas, uma delas relativa a certo evolucionismo, porque ele atribui à tecnologia simbólica, chamada matemática, uma posição privilegiada como fator propulsor do desenvolvimento cultural. ${ }^{6}$

Existe portanto uma situação de impasse na área de etnomatemática que diz respeito à polaridade universal/particular. Tal impasse está presente no próprio nome etnomatemática, a primeira parte da palavra sendo relativa a etnia, que pressupõe a diversidade, enquanto a segunda parte, matemática, refere-se a uma disciplina da academia, tida como universal. Márcio D’Olne Campos (1995), falando das etnociências em geral, chega a afirmar que:

Partiremos do termo genérico "etno-x", onde x denomina uma disciplina ou especialidade pertencente à classificação metodológica do conhecimento dentro da academia [...] Concordo que o termo etno-x carrega a marca do etnocentrismo, ainda que venha insistindo na possibilidade de atenuação dessa carga por uma etnociência $(\mathrm{x}=$ ciência) redefinida e recuperada, tal como vem sendo praticada por novas correntes da etnobiologia e da etnoastronomia. (p. II-21)

O etnocentrismo a que se refere o autor acima diz respeito a considerar preexistentes as disciplinas da academia que viriam depois do prefixo etno: biologia, astronomia, ou qualquer outra, como a matemática, por exemplo. Quando o pesquisador entra em contato com outra cultura, deve adotar uma postura aberta, despojar-se das classificações próprias de sua cultura de origem, para poder compreender outros sistemas de classificação do conhecimento. O prefixo etno carrega também um certo grau de preconceito, se associado à disciplina de nossa cultura; por exemplo, o outro passa a ser visto como sendo também capaz de desenvolver uma biologia, uma astronomia,

6 Consultar, a esse respeito, Knijnik (1996) e autores citados por essa pesquisadora, como Connors (1990) e Dowling (1991). uma matemática, mas de outra natureza, de uma natureza etno. A disciplina da academia passa a ser vista como uma referencial, como um ideal a ser atingido numa linha evolutória.

O principal sistematizador do termo etnomatemática, Ubiratan D’Ambrósio, talvez consciente do risco de etnocentrismo, dá uma definição um pouco diferente para a palavra:

A aproximação etimológica a que nos referimos nos permite dizer que etnomatemática é a arte ou técnica (techné=tica) de explicar, de entender, de se desempenhar na realidade (matema), dentro de um contexto cultural próprio (etno). (D’Ambrósio, 1993, p. 9)

Mais adiante é ainda mais esclarecedor:

Na verdade, diferentemente do que sugere o nome, etnomatemática não é apenas o estudo de "matemáticas das diversas etnias". Para compor a palavra etno matemática utilizei as raízes tica, matema e etno para significar que há várias maneiras, técnicas, habilidades (tica) de explicar, de entender, de lidar e de conviver (matema) com distintos contextos naturais e socioeconômicos da realidade (etno).

(D’Ambrósio, 1996, p. 111-112)

Nessa perspectiva, o objeto de estudo da etnomatemática passa a ser bastante abrangente, confundindo-se com o estudo dos processos de geração, organização e transmissão do conhecimento em diversos sistemas culturais. A matemática, enquanto disciplina da academia, passa a ser também uma etnomatemática, produzida por um grupo identificável, os matemáticos, que possuem valores, rituais e códigos próprios.

Talvez uma das formas de resolver esse impasse seja concordar com Barton (1995) quando diz:

Não apenas a definição de etnomatemática é construída nos termos de uma cultura específica, como também a prática etnomatemática também precisa ser culturalmente específica. Estudar a maneira pela qual outra cultura reconhece práticas e conceitos particulares é um exercício 
interpretativo de uma cultura sobre outra. Este tipo de atividade, necessariamente, precisa usar a forma de discurso do intérprete. Particularmente, o etnomatemático estará usando os conceitos da matemática. (p. 217, tradução minha)

A outra cultura pode não ter a categoria matemática, mas mesmo assim o olhar etnomatemático (no “estar aqui”) será a partir dessa mesma categoria matemática, mesmo que, durante o trabalho de campo (o "estar lá") o etnomatemático procure aproximar-se das categorias de classificação do grupo estudado. A postura do pesquisador em etnomatemática demanda essa flexibilidade, na tentativa de interpretar as formas de raciocinar de um outro. Mas, em certo sentido, será sempre uma tradução.

Existe uma dimensão política na proposta da etnomatemática. Tornar visíveis os saberes de uma cultura que se encontra, por fatores históricos, políticos ou econômicos, dominada por outra, é dar poder a esta última. Muitos pesquisadores em etnomatemática, apesar de pequenas diferenças de enfoque, têm demonstrado consciência da capacidade de empowerment inerente aos objetivos e resultados de suas pesquisas. Paulus Gerdes (1995) é explícito quando diz:

Aqui reside um desafio: a herança cultural africana deveria ser o ponto de partida para o desenvolvimento do currículo em matemática de maneira a melhorar sua qualidade, aumentar a autoconfiança cultural e social de todos os alunos, tanto meninas como meninos. A pesquisa etnomatemática pode contribuir para encontrar algumas respostas. (p. 199, tradução minha)

Trabalhando na Moçambique recém-libertada de séculos de colonização portuguesa, Gerdes tem uma perspectiva educacional libertária, onde insere um dos objetivos da etnomatemática: o de buscar a melhoria do ensino de matemática, implantando-o no contexto cultural de alunos e professores.

Outra pesquisadora, Gelsa Knijnik (1996), em seu trabalho com membros do movimento dos sem-terra, no sul do Brasil, preocupa-se com a dimensão política de sua Abordagem etnomatemática. Esta seria:
[...] a investigação das tradições, práticas e concepções de um grupo social subordinado (quanto ao volume e composição de capital social, cultural e econômico) e o trabalho pedagógico que se desenvolve com o objetivo de que o grupo: a) interprete e decodifique seu conhecimento; b) adquira o conhecimento produzido pela matemática acadêmica e estabeleça comparações entre o seu conhecimento e o conhecimento acadêmico, analisando as relações de poder envolvidas no uso destes dois saberes. (p. 88)

Estaria a dimensão política da etnomatemática atrelada à sua dimensão pedagógica, como parecem indicar os dois autores acima? Estando eu trabalhando com um grupo em dupla situação de desvantagem na sociedade, por serem moradores de favela e terem sido excluídos precocemente do sistema escolar, preocupei-me desde o início da pesquisa com essa dimensão. Não tinha, no entanto, uma proposta de intervenção pedagógica no decorrer do estudo, mas estava consciente da existência das relações de poder que se estabelecem na situação pesquisadorpesquisado. No momento, cabe-me concordar com as palavras de D'Ambrósio (2001), atribuindo a todas as etapas da pesquisa em etnomatemática uma função de resgate das raízes culturais de um outro, resgate esse que confere poder ao lado desprivilegiado:

A etnomatemática se encaixa nessa reflexão sobre a descolonização e na procura de reais possibilidades de acesso para o subordinado, para o marginalizado e para o excluído. A estratégia mais promissora para a educação, nas sociedades que estão em transição da subordinação para a autonomia, é restaurar a dignidade de seus indivíduos, reconhecendo e respeitando suas raízes. Reconhecer e respeitar as raízes de um indivíduo não significa ignorar e rejeitar as raízes do outro, mas, num processo de síntese, reforçar suas próprias raízes. Essa é, no meu pensar, a vertente mais importante da etnomatemática. (p. 42)

No campo da educação de jovens e adultos, esse resgate das raízes do indivíduo, de sua dignidade cultural, através do reconhecimento de estratégias de re- 
solução de problemas que fogem da matemática convencional, atuaria positivamente num dos maiores inibidores da aprendizagem do aluno adulto, que é seu sentimento de autodesvalia.

Trabalhar dentro de uma proposta etnomatemática com um universo multicultural, como é uma turma de jovens e adultos, representava um desafio, porque se buscava entender as formas culturais de pensamento matemático de um outro, quando, na realidade, devido à diversidade de origem geográfica, faixa etária, ocupação, entre outras características dos educandos, existiam diversos outros naquele contexto.

\section{A pesquisa etnográfica no Morro de São Carlos}

A etnografia, prática essencial dos estudos antropológicos, foi considerada a linha de pesquisa mais adequada para o estudo dos saberes de um grupo de jovens e adultos, em seus contextos de vida cotidiana. Somente um contato longo no campo, com momentos indissociáveis e articulados: o "estar lá" e o "estar aqui” (D’Olne Campos, 2001), ou seja, procurando familiarizar-se com o "exótico" e tornando exótico o que era familiar (Da Matta, 1978), poderia proporcionar um diálogo com o outro (representado aqui pelos jovens e adultos), com sua cultura, com seu universo de significados. O pesquisador é parte integrante do processo de conhecimento e descoberta, e, portanto, o "fato etnográfico" (Peirano, 1995) já indica que houve seleção no que foi observado e interpretação no relato: a subjetividade, ao invés de negada, passa a ser matéria-prima do pesquisador etnográfico.

O local escolhido para a pesquisa de campo foi o Morro de São Carlos, comunidade de baixa renda da cidade do Rio de Janeiro, com cerca de setenta anos de existência, com alto índice de ocupação demográfica. Fiz essa escolha após um contato que estabeleci com a coordenadora de projetos educativos na igreja católica local, porque lá havia um curso de jovens e adultos freqüentado por moradores da comunidade. Essa particularidade permitiria um contato simultâneo com o contexto escolar e com o ambiente exter- no à escola, característica importante para um estudo que buscava as relações entre os conhecimentos matemáticos escolares e aqueles da vida cotidiana. Pelo fato de os educandos compartilharem a mesma escola e o mesmo local de moradia, poderia considerá-los, senão um grupo cultural, ao menos um grupo social.

Desenvolvi portanto uma pesquisa etnográfica no Morro de São Carlos de maio a dezembro de 2000, com diversos retornos posteriores à comunidade até o ano de 2003. A rotina de duas turmas do curso de jovens e adultos local foi acompanhada por meio de observação participante, com registro minucioso em caderno de campo. Paralelamente, e à medida que se estabelecia uma relação de confiança mútua, pude realizar observações da vida comunitária, circulando pela favela, visitando as moradias e alguns pontos de referência locais. Desse modo, realizei entrevistas gravadas com educandos, professoras, coordenadoras do projeto e outros moradores da comunidade. Além das técnicas citadas, utilizei também na minha pesquisa a documentação fotográfica e a análise de documentos escritos, formais e informais.

\section{Resultados e discussão}

Tratarei aqui dos principais resultados desta pesquisa sobre conhecimentos matemáticos escolares e extra-escolares de jovens e adultos do Morro de São Carlos, partindo de uma visão mais ampla para um olhar mais focalizado. Três grandes categorias foram construídas, de acordo com o contexto do qual estou interpretando esses conhecimentos: relações quantitativas e espaciais na comunidade, os conhecimentos matemáticos na vida cotidiana e a matemática escolar e a matemática do dia-a-dia.

\section{Relações quantitativas e espaciais na comunidade}

A numeração das ruas do Morro de São Carlos merece destaque pela forma como está organizada. Seguindo-se por uma rua qualquer da favela, observam-se casas numeradas, mas com as seguintes di- 
ferenças em relação a outras partes da cidade: a sequência numérica nem sempre é crescente, não há um padrão do tipo casas de número par à direita, de número ímpar à esquerda, e ocorrem também repetições do mesmo número de casa. Tamanha diversidade, além de estar relacionada à história de ocupação não-planejada do morro, explica-se também pelas mudanças nos critérios definidos pela associação de moradores e pelo crescimento demográfico da comunidade. Assim, se uma casa é 20, a seguinte pode ser a 21 , porque sempre prevaleceu o critério de proximidade. Porém, se uma moradia é construída no meio das duas, esta pode passar a ser $20 a$. O crescimento na vertical do morro, com a construção de mais andares para uma mesma casa, leva à adoção de critérios não numéricos para identificação das residências: "Ali é o 20 da Dona Maria". 7 Os números das casas parecem funcionar como nomes, dos quais os moradores têm alguma autonomia na escolha.

Outro aspecto significativo relativo à organização espacial do Morro de São Carlos pode ser encontrado na inversão de mão de direção, que acontece na subida da ladeira que dá acesso à comunidade. É a chamada mão inglesa, estabelecida como regra de trânsito própria da comunidade para facilitar o deslocamento dos veículos motorizados em uma subida muito íngreme, aproveitando uma curva acentuada. Tal inversão de mão de direção dificilmente pode ser prevista por pessoas estranhas que chegam na comunidade, pelo fato de contrariar as regras de trânsito oficiais, e por não haver uma sinalização clara para o motorista no local da curva. Parece refletir uma preocupação maior dos moradores com os limites da realidade (condições geográficas do morro) do que com as leis de trânsito oficiais, assim como um isolamento do mundo da favela em relação ao resto da cidade.

Outro contexto no qual podem ser observadas representações quantitativas e espaciais próprias dos moradores do Morro de São Carlos é no sistema de transporte local, realizado por meio de kombis. Não

\footnotetext{
7 Dados coletados em 23 jan. 2003 (Diário de campo).
}

existe uma regularidade nos horários de subida do veículo, pois esta é condicionada ao critério econômico de um número mínimo de passageiros. No entanto, normas sociais também parecem intervir nessa regra, como é o caso de um carro, cuja lotação é de dez passageiros, subindo com dezessete pessoas, porque o limite não inclui crianças até 8 anos, que não pagam se permanecerem em pé ou no colo de um adulto pagante. Mais do que a preocupações relativas ao número máximo de passageiros para que a kombi se desloque com segurança, a flexibilidade na representação da quantidade parece atender a demandas sociais. Se tivessem que arcar com as despesas de um ou mais filhos, os adultos pagantes provavelmente deixariam de utilizar esse meio de transporte, o que viria a inviabilizar seu funcionamento na comunidade.

\section{Os conhecimentos matemáticos na vida cotidiana: estratégias de sobrevivência}

A atividade de compras no mercado foi a mais citada pelos entrevistados quando indagados sobre sua matemática do cotidiano. Ao falar dela, os adultos do Morro de São Carlos deram informações importantes sobre seus procedimentos de cálculo e os sentimentos envolvidos nas decisões a serem tomadas naquela situação. Um aspecto comum, relativo à motivação para o raciocínio matemático, apareceu em todas as falas, como nas que se seguem:

Se uma coisa é dois reais e oitenta centavos, eu falo: é três reais. Eu falo assim... pra mim poder saber se o meu dinheiro vai dar pra mim pagar! Se uma coisa é um real e oitenta, eu falo: dois reais. Deu cinco e quarenta, eu ponho seis reais. Eu faço assim, que aí eu pago e sei que não vou passar vergonha no caixa. (Entrevista 7, realizada em 28/9/2000)

[...] eu vou anotando o preço das coisas e vou anotando, mas sempre arredondando, tá, pra mim quando chegar na caixa num passar pela situação de não dar o dinheiro, né? (Entrevista 3, realizada em 15/9/2000) 
A necessidade de estimar antes de pagar parece vir de uma organização doméstica com papel moeda, na qual o arredondamento para o próximo valor inteiro superior, calculando exagerado - de acordo com as palavras de um educando - serve a dois propósitos interrelacionados: avaliar o montante a ser pago pelas compras e não passar vergonha no caixa, ou seja, evitar a situação constrangedora de não se ter dinheiro suficiente para o pagamento das mesmas.

O sentimento expresso de não querer passar vergonha foi mencionado por todos os educandos entrevistados, e pode ser interpretado de diferentes maneiras. Uma delas é a imagem negativa à qual são destinatárias as pessoas das camadas de menor poder aquisitivo, e particularmente os moradores de favela (Vergne, 2002). Talvez por habitarem em uma comunidade dominada pelo tráfico de drogas, onde os limites entre trabalhadores/bandidos não sejam claramente percebidos pela sociedade de fora, sentem necessidade de evitar passar por uma situação na qual esse tipo de julgamento poderia ser feito sobre eles.

Uma outra possível hipótese explicativa para o sentimento acima apresentado está na baixa autoestima do educando jovem/adulto. Paulo Freire (1974) é um dos autores que mencionam a existência de um sentimento autodepreciativo entre educandos de baixa escolaridade: "A autodesvalia é outra característica dos oprimidos. Resulta da introjeção que fazem eles da visão que deles têm os opressores" (p. 54). Essa introjeção a que se refere Paulo Freire resulta numa alienação sobre as condições concretas, sociais, que os levaram a se encontrar na posição de "oprimidos". Numa sociedade urbana, letrada, ter sido excluído precocemente da escola não apenas limita o acesso ao mercado de trabalho, como também parece trazer danos de natureza psicológica para o indivíduo nessa situação, levando-o a crer em sua incapacidade pessoal de aprender, que ele transfere para outros setores de sua vida. Talvez possamos deduzir que essas pessoas associem o fato de não ter o suficiente para pagar a um sentimento de incapacidade, de inferioridade, que produz a vergonha. Nessa situação, como em outras da pesquisa, o raciocínio matemático passa a ser uma ferramenta voltada para a sobrevivência, equilibrando um orçamento apertado e a auto-estima do indivíduo.

$\mathrm{O}$ uso de procedimentos de cálculo mental em contextos da vida cotidiana foi outro ponto comum presente entre os sujeitos de pesquisa, às vezes por si só, outras vezes associado a outra forma de cálculo, escrito ou com apoio de calculadora. Em alguns casos o calcular de cabeça aparece associado a uma marca de identidade cultural, como fica claro na fala de um educando, abaixo:

\footnotetext{
[...] a gente trabalha na cabeça! O pessoal do Norte tá mais apto que o pessoal do Sul... O pessoal do Sul agora é tudo máquina, maquinazinha, né? Lá no Norte é na cabeça, ainda que funciona... ao menos funciona! (Entrevista 10, realizada em 9/10/2000)
}

Para esse educando, o calcular de cabeça passa a ser, então, um elemento diferenciador entre os outros (sulistas, usuários de tecnologias modernas) e nós (nordestinos, moradores de favela, detentores de saberes tradicionais próprios). A forma como esses procedimentos de cálculo mental foram aprendidos parece ser também definidora dessa sua característica de marca cultural. Muitos declararam ter aprendido a fazer contas de cabeça na infância, com algum parente mais velho, que, apesar de ser analfabeto, era bemsucedido em situações cotidianas que envolviam representações numéricas.

A manutenção dessas estratégias de cálculo mental, mesmo entre os sujeitos mais escolarizados, parece representar uma forma de resistência dessa população à sociedade tecnológica que os exclui, uma maneira de conquistar um "lugar próprio" (De Certeau, 1999) nessa sociedade, de não serem anulados por ela.

Outro aspecto que se destacou na pesquisa foi a importância dos números pequenos entre os alunos jovens e adultos pesquisados. Posso citar o caso de uma educanda costureira, que trabalha dividindo tarefas com sua cunhada, cada uma delas representando apenas uma parte de uma engrenagem maior, que acarreta na produção completa de uma peça de roupa. São pagas por peça, e o que arrecadam está sempre dentro 
dos valores dos centavos. Nesse contexto, uma diferença de cinco centavos é representativa, como ela diz:

[...] ela me pagava vinte e cinco um biquíni desses, agora ela vai me pagar trinta. (Entrevista 14, realizada em 15/11/2000)

Cabe observar que, nessa situação, cinco centavos, embora seja um valor baixo, representa $20 \%$ de aumento sobre o valor anterior, de vinte e cinco centavos.

Curiosamente, a importância dos centavos passa a ter outra conotação quando se trata de estimar o valor das compras no mercado. Muitos adultos aparentemente ignoram os centavos nesse momento, arredondando para cima o valor dos produtos, para não arriscarem de não ter o dinheiro na hora do caixa. Como diz um educando:

[...] a gente calcula também um pouco exagerado, né? (Entrevista 9, realizada em 7/10/2000)

Essa estratégia pode parecer inversa da outra, porque nesse caso os centavos aparentemente estão sendo descartados no processo de cálculo. Mas, na realidade, os centavos continuam sendo importantes nesse tipo de heurística de arredondamento - eles passam a ser superestimados, ou seja, continuam presentes.

Todas essas situações descritas respondem a uma necessidade maior: a de sobrevivência.

\section{A matemática escolar e a matemática do dia-a-dia}

Em suas falas, os jovens e adultos do Morro de São Carlos tenderam a diferenciar a matemática do dia-a-dia da matemática aprendida na escola, visto que a necessidade de sobrevivência demarca as fronteiras entre os dois tipos de conhecimento. O depoimento de uma educanda ilustra essa distinção entre um saber mais teórico e um saber voltado para a resolução de problemas práticos:

Que na escola é a teoria, que a gente tá aprendendo. E na prática, a gente já tem a prática do dia-a-dia, né? Que se a gente não tivesse a prática, a gente não tinha condições de sobreviver. Como é que a gente ia sobreviver? Sem saber nada, sem saber contar, sem saber vender, sem saber contar, sem saber calcular. Realmente... as coisas começam pela comida, pelo sabão pra botar na máquina de lavar roupa... (Entrevista 10, realizada em 9/10/2000)

O pragmatismo do conhecimento matemático do cotidiano, presente na fala da aluna, também aparece em outras pesquisas em etnomatemática, como na de Costa (1998). No desempenho das tarefas do cotidiano, a leitura formalizada dos saberes não parece ser tão importante como saber desempenhar as tarefas de maneira a ser bem-sucedido. Outro aspecto diferenciador entre esses dois tipos de saberes é que "as soluções estão impregnadas pelas condições circunstanciais nas quais o problema foi gerado" (Carvalho, 1997, p. 13). Outra diferença apontada pelos sujeitos refere-se à maior flexibilidade da matemática do cotidiano, como explica a aluna, comparando algumas de suas práticas de dona de casa que envolvem representações numéricas com a precisão da escrita nos algoritmos escolares:

É diferente. Diferente e difícil... Tudo certinho! Se não, se a gente errar um algarismo... Em caso se eu... cinco quilos, mas se eu botar cinco quilos e cem, a máquina bate... $\mathrm{O}$ feijão tem que ficar quarenta minutos, se ficar quarenta e cinco também, não tem problema. (Entrevista 7, realizada em 28/9/2000)

A educanda opõe a exigência escolar da resposta correta a uma certa flexibilidade de situações cotidianas que envolvem representações matemáticas. Essa concepção de matemática enquanto ciência comprometida com a precisão, com a unicidade de resultados, está muito presente em nossa sociedade.

Mas os resultados de minha pesquisa indicaram ainda que tal polarização também pode ser por vezes invertida, ou seja, que algumas situações da vida diária exigem muita precisão, ou que pode haver maior complexidade nos procedimentos extra-escolares do que nos escolares. Cito o exemplo de um educando, 
vendedor de uma mercearia da comunidade, que vi utilizando em seu trabalho diversos procedimentos mentais e escritos, com ou sem apoio da calculadora, como o cálculo de porcentagem. Enquanto isso, na escola, pude observá-lo errando um problema proposto, ao resolvê-lo de forma mecânica, sem fazer uma verdadeira interpretação deste.

Conhecimentos matemáticos prévios de jovens e adultos, construídos em contextos diversificados, ${ }^{8}$ também interagem com a matemática que está sendo ensinada na escola. Uma das formas pelas quais observei tal interação foi a que optei chamar de função confirmadora do uso simultâneo de diferentes procedimentos, que se caracteriza pela tentativa de resolução de uma situação problema - por exemplo, um exercício proposto pela professora - utilizando-se paralelamente de algum procedimento de cálculo que se domina. Esse segundo procedimento tem a função de confirmar o resultado obtido no primeiro, aparentemente porque o educando não tem muita confiança em seu desempenho no procedimento que lhe é menos familiar. ${ }^{9}$ Buscando certificar-se de suas respostas, os jovens e adultos utilizam-se de cálculo mental, procedimentos escritos próprios, ou mesmo outro procedimento escolar que já dominam. A concepção de matemática como ciência da exatidão pode ter ajudado a disseminar essas práticas, mas a estratégia da confirmação pode ser também interpretada como uma forma ativa de lidar com um sentimento de culpa pelo erro, de que fala Garcia (1985), comum entre educandos de baixa escolaridade.

8 Estão incluídos nesses conhecimentos aqueles aprendidos em passagens anteriores pela escola, que Fonseca (2001) denominou de "reminiscências da matemática escolar".

${ }^{9}$ Essa estratégia serve, nas palavras de um dos educandos, "pra tirar as dúvidas" (Entrevista 4, realizada em 24/9/2000). Os procedimentos variavam, mas o objetivo de confirmar o resultado era o mesmo, aparentemente motivado por um sentimento de insegurança sobre a exatidão do primeiro.

\section{Considerações finais}

Os resultados da pesquisa apresentaram algumas respostas para a pergunta: como a matemática escolar e a matemática da vida cotidiana se relacionam em um grupo de jovens e adultos da classe trabalhadora?

Para os jovens e adultos do Morro de São Carlos, diferentes tipos de conhecimento matemático parecem pertencer a dois mundos distintos, em que um tipo de saber atende às necessidades de um mundo, e outro tipo de saber às de outro. A separação já começa na forma de nomear: matemática, para muitos educandos, é somente aquilo que se aprende na escola, ou os conhecimentos que outros, mais estudados, dominam. Duas falas de educandos merecem ser apresentadas:

Sabe que eu não tinha pensado que a gente tava trabalhando com matemática? (Entrevista 7, realizada em 28/9/2000)

[Na vida...] a gente aprende conta, a matemática só se aprende no colégio. (Entrevista 10, realizada em 9/10/2000)

De fato, a valorização da matemática formal é tanta, em nossa sociedade, que este conhecimento serve como um valor de referência, quando comparada pelos adultos com seus conhecimentos práticos. Estes últimos podem também ser reconhecidos como matemática, ou então são vistos como diferentes de matemática. Incluindo-se ou negando-se a presença da matemática no cotidiano, ela está sendo, de qualquer maneira, mitificada.

Uma das explicações para essa separação entre o mundo da vida cotidiana e o mundo da escola, em relação aos conhecimentos matemáticos, está na própria sociedade e em suas hierarquias de poderes e saberes. O processo de alienação, que torna os conhecimentos próprios dos jovens e adultos de certa forma invisíveis, recebe uma explicação de Munir Fasheh (1991):

A hegemonia se caracteriza pelo que ela inclui mas também pelo que ela exclui: pelo que ela apresenta como 
marginal, julga inferior e torna invisível. O efeito da educação hegemônica é tal, que se torna quase possível definir o ambiente real por aquilo que a educação formal marginaliza ou exclui. (p. 59, tradução minha)

Essa valorização social do saber escolar hegemônico leva os jovens e adultos a procurar ter acesso a ele por meio do reingresso numa escolarização, mesmo que tardia.

Outra observação que pode ser feita em relação a essa separação mundo da vida cotidiana/mundo escolar, é que o contexto parece intervir nessa representação tão dicotomizada. O mundo da favela é um mundo à parte dentro da cidade grande: seus habitantes têm sido estigmatizados desde os primórdios da formação da cidade. As reações a esse processo de exclusão social podem aparecer de diferentes formas. Até os saberes construídos por esse grupo social, os matemáticos dentre eles, parecem ser uma estratégia de afirmação de identidade. De algum modo, para dizer eu existo o morador do São Carlos afirma eu penso diferente. Tanto as regras sociais particulares do Morro, identificadas nessa pesquisa, quanto a conservação de práticas de raciocínio próprias, como o cálculo mental, parecem ser formas de resistir a um processo de anulação de identidade.

Tudo indica que, no mundo da vida cotidiana, calcula-se, estima-se, mede-se, entre outras habilidades matemáticas, para se conseguir sobreviver nas condições adversas que fazem parte da vida diária de um excluído do sistema escolar, morador de comunidade de baixa renda. Driblar um orçamento doméstico apertado, desempenhar-se bem nas tarefas profissionais, dominar informações básicas para orientação espacial na cidade, são motivações para que os jovens e adultos trabalhadores construam conhecimentos matemáticos novos, utilizem os que já dominam, rememorem procedimentos aprendidos no passado. Os conhecimentos matemáticos do cotidiano atendem primordialmente às necessidades de sobrevivência econômica e social. Os fatores afetivo-emocionais, que se configuram como potenciais de auto-estima, também apareceram como um significativo eixo de análise para o processo de construção/aprendizagem/ utilização de conhecimentos matemáticos dos jovens e adultos do Morro de São Carlos.

Buscando possíveis contribuições deste meu estudo para as práticas pedagógicas em educação de jovens e adultos, teria algumas considerações a fazer.

Em primeiro lugar, esta pesquisa representou uma tentativa de dar voz a um grupo de jovens e adultos do ensino fundamental, sobre suas formas de conhecimento. Esse mundo da vida cotidiana que parece estar tão afastado do mundo da escola tem muito a ensinar a educadores matemáticos. Os conhecimentos matemáticos do cotidiano são ricos, complexos, lógicos. Precisam ser legitimados pela escola, para facilitar a aprendizagem desses outros conhecimentos matemáticos, os formais, que os jovens e adultos também buscam acessar.

Em segundo lugar, acredito que o afastamento mundo da vida cotidiana/mundo da escola talvez viesse a ser menor se professores e profissionais da educação compreendessem os motivos que levam os adultos a resistir a uma simples passagem dos conhecimentos matemáticos práticos para os conhecimentos matemáticos escolares. Não se trata de uma ponte, mas antes de um diálogo que deve ser respeitoso de parte a parte. Se há respeito, há troca. Se há horizontalidade, há menos resistência. A busca de uma possível integração dos conhecimentos matemáticos escolares com os do cotidiano não pode ser um pretexto para a desvalorização do conhecimento primeiro do educando. Talvez porque sinta essa desvalorização oculta, esse adulto não dialoga como poderia; portanto, não aprende como poderia. Concordo com Pedro Garcia (1984) quando diz que "é a relação de poder que deve mudar para que o agente possa decodificar o que os grupos populares têm a dizer" (p. 101).

A pesquisa também levantou algumas reflexões para a área da etnomatemática. Uma delas diz respeito à caracterização do grupo cultural no qual foram investigados os saberes, técnicas e práticas a partir de um enfoque matemático, particularmente em um contexto urbano de uma diversidade cultural muito grande. Os resultados indicaram que os três denominado- 
res comuns do grupo estudado - pessoas com baixa escolaridade, de classe econômica desfavorecida e moradores de favela - tenderam a aproximar esses sujeitos no que diz respeito às formas de construir/ representar/utilizar conhecimentos matemáticos, assim como em relação aos fatores afetivo-emocionais que motivam o raciocínio e a aprendizagem. A condição de excluído, portanto, configurou-se como um fator de identidade entre eles, superando as diferenças culturais existentes no grupo.

\section{MARIACECILIA DE CASTELLO BRANCO FANTINATO,}

doutora em educação pela Universidade de São Paulo, é professora adjunta da Faculdade de Educação da Universidade Federal Fluminense. Desde 1995 vem trabalhando nas áreas de educação matemática e educação de jovens e adultos. Pertence ao Grupo de Estudos e Pesquisas em Etnomatemática da USP desde 1999, com o qual participou da organização do $1^{\circ}$ Congresso Brasileiro de Etnomatemática (CBEm1), em 2000. Desde 2003 coordena o Núcleo de Estudos e Pesquisas em Educação Matemática da UFF (NEPEM-UFF). Publicou recentemente: Calculando exagerado para não passar vergonha no caixa: representações quantitativas e espaciais entre jovens e adultos do Morro de São Carlos (Movimento, $\mathrm{n}^{\circ} 8$, set. 2003, p. 131-140); Contribuições da etnomatemática na educação de jovens e adultos: algumas reflexões iniciais. In: RIBEIRO, J. P. M., DOMITE, M. C. S., FERREIRA, R. (orgs.). Etnomatemática: papel, valor e significado (São Paulo: Zouk, 2004, p. 171-184).E-mail: mcfantinato@hotmail.com

\section{Referências bibliográficas}

BARTON, B., (1995). Making sense of ethnomathematics: ethnomathematics is making sense. Educational Studies in Mathematics, v. 31, $\mathrm{n}^{\circ}$ 1-2, p. 201-233.

BISHOP, A. J., (1988). Mathematical enculturation: a cultural perspective on mathematics education. Dordrecht: Kluwer Academic Publishers.

CARRAHER, T., CARRAHER, D., SCHLIEMANN, A., (1989). Na vida dez, na escola zero. São Paulo: Cortez.

CARVALHO, D. L., (1995). A interação entre o conhecimento matemático da prática e o escolar. Tese de doutorado. Faculdade de Educação da Universidade Estadual de Campinas.
, (1997). A educação matemática dos jovens e adultos nas séries iniciais do ensino básico. Alfabetização e Cidadania, $\mathrm{n}^{\circ} 6$, p. 11-24.

CONNORS, J., (1990). When mathematics meets antropology: the need for interdisciplinary dialogue. Education Studies in Mathematics, The Netherlands, $n^{\circ} 21$, p. 461-469.

COSTA, W. N. G., (1998). Os ceramistas do vale do Jequitinhonha: uma investigação etnomatemática. Dissertação de mestrado. Faculdade de Educação da Universidade Estadual de Campinas.

DA MATTA, R., (1978). O ofício de etnólogo, ou como ter “anthropological blues". In: NUNES, E. de O. (org.). A aventura sociológica. Rio de Janeiro: Zahar. p. 23-35.

D’AMBRÓSIO, U., (1993). Etnomatemática: um programa. A Educação Matemática em Revista, Blumenau, v. 1, n 1, p. 5-11. , (1996). Educação matemática: da teoria à prática. Campinas: Papirus.

, (2001). Etnomatemática: elo entre as tradições e a modernidade. Belo Horizonte: Autêntica (Coleção Tendências em Educação Matemática).

D’OLNE CAMPOS, M., (1995). Discussão teórico-metodológica: aspectos etnocientíficos. Relatório técnico-científico do projeto temático FAPESP: Homem, saber e natureza. v. 1. Campinas, Aldebarã: Observatório a Olho Nu/IFCH/UNICAMP. , (2001). Etnociência ou etnografia de saberes e técnicas? In: Métodos de coleta e análise de dados em etnobiologia, etnoecologia e disciplinas correlatas. Anais do Seminário de Etnobiologia e Etnoecologia do Sudeste (29/11 a 01/12/ 2001), Rio Claro, p. 47-92.

DE CERTEAU, M., (1999). A invenção do cotidiano: artes de fazer. Petrópolis: Vozes.

DOWLING, P., (1991). The contextualizing of mathematics: towards a theoretical map. In: HARRIS, M. (ed.). School, mathematics and work. Hampshire: The Falmer Press, p. 93-120.

DUARTE, N., (1985). O compromisso político do educador no ensino da matemática. In: OLIVEIRA, B. A., DUARTE, N. Socialização do saber escolar. São Paulo: Cortez, p. 77-89.

FANTINATO, M. C. C. B., (2003). Identidade e sobrevivência no Morro de São Carlos: representações quantitativas e espaciais entre jovens e adultos. Tese de doutorado. Faculdade de Educação da Universidade de São Paulo.

FASHEH, M., (1991). Mathematics in a social context: math 
within education as praxis versus math within education as hegemony. In: HARRIS, M. (ed.). School, mathematics and work. Hampshire: The Falmer Press, p. 57-61.

FERREIRA, E. S., (1997). Etnomatemática: uma proposta metodológica. Rio de Janeiro: Universidade Santa Úrsula (Série Reflexão em Educação Matemática, v. 3).

FONSECA, M. C. F. R., (2001). Lembranças da matemática escolar: a constituição dos alunos da EJA como sujeitos da aprendizagem. Educação e Pesquisa, São Paulo, Revista da Faculdade de Educação da USP, v. 27, nº 2, p. 339-354.

, (2002). Educação matemática de jovens e adultos: especificidades, desafios e contribuições. Belo Horizonte: Autêntica.

FREIRE, P., (1974). Pedagogia do oprimido. Rio de Janeiro: Paz e Terra.

GAL, I., (2000). The numeracy challenge. In: GAL, I. (ed.). Adult numeracy development: theory, research, practice. Cresskill, NJ: Hampton Press, p. 9-31.

GARCIA, P. B., (1984). Educação popular: algumas reflexões em torno da questão do saber. In: BRANDÃO, C. R. (org.). A questão política da educação popular. São Paulo: Brasiliense, p. $88-121$.

(1985). O olho do outro: algumas anotações sobre alfabetização de adultos. In: BEZERRA, A. (ed.). Alfabetização de adultos. Petrópolis: Vozes, p. 9-18 (Cadernos de Educação Popular 8).

GAY, J., COLE, M., (1967). The new mathematics in an old culture. New York: Holt, Rinehart and Winston.

GERDES, P., (1995). Women, art and geometry in Southern Africa. Trenton, NJ/Asmara, Eritrea: Africa World Press.

HARRIS, M., (2000). Mathematics and the traditional work of women. In: GAL, I. (ed.). Adult numeracy development: theory, research, practice. Cresskill, NJ: Hampton Press, p. 269-301.

KNIJNIK, G., (1996). Exclusão e resistência: educação matemática e legitimidade cultural. Porto Alegre: Artes Médicas.

LINDENSKOV, L., WEDEGE, T., (2001). Numeracy as an analytical tool in mathematics education and research. Centre for Research in Learning Mathematics, Publication $n^{\circ} 31$.

LOPES, A. J., (1997). Explorando o uso da calculadora no ensino de matemática para jovens e adultos. Alfabetização e Cidadania, $\mathrm{n}^{\circ}$ 6, p. 67-79.

MACHADO, M. M., (1999). Política educacional para jovens $e$ adultos: lições da história. São Paulo: Pontifícia Universidade Católica de São Paulo, Programa de Estudos Pós-Graduados em Educação (mimeo.).

MONTEIRO, A., (1998). Etnomatemática: as possibilidades pedagógicas num curso de alfabetização para trabalhadores rurais assentados. Tese de doutorado. Faculdade de Educação da Universidade Estadual de Campinas.

OLIVEIRA, H. D. L., (2002). Entre quartas, braças e hectares: a educação matemática enraizada no rural. Alfabetização e Cidadania, $\mathrm{n}^{\circ}$ 14. São Paulo: Rede de Apoio à Ação Alfabetizadora do Brasil, p. 43-51.

OLIVEIRA, M. K., (1999). Jovens e adultos como sujeitos de conhecimento e aprendizagem. Revista Brasileira de Educação, $\mathrm{n}^{\circ} 12$, p. 59-73.

PEIRANO, M., (1995). A favor da etnografia. Rio de Janeiro: Relume-Dumará.

RIBEIRO, V. M. M. (coord.), (1997). Educação de jovens e adultos: proposta curricular para o primeiro segmento do ensino fundamental. São Paulo: Ação Educativa / Brasília: MEC.

SINGH, E., (2002). Adult numeracy and new technology in the UK. In: CONGRESSO INTERNACIONAL DE ETNOMATEMÁTICA, 2. Ouro Preto. CD-ROM, p. 1-4.

TOLEDO, M. E. R. O., (1997). Os registros matemáticos dos adultos. Alfabetização e Cidadania, São Paulo: Rede de Apoio à Ação Alfabetizadora do Brasil, nº 6, p. 35-41. , (2002). Numeramento, metacognição e aprendizagem matemática de jovens e adultos. In: REUNIÃO ANUAL DA ASSOCIAÇÃO DE PÓS-GRADUAÇÃO E PESQUISA EM EDUCAÇÃO, 25., Caxambu: ANPEd. CD-ROM, p. 1-15.

VERGNE, C. M., (2002). A história dos rostos esquecidos: a violência no olhar sobre os moradores de favelas cariocas. Dissertação de mestrado. Departamento de Psicologia da Pontifícia Universidade Católica do Rio de Janeiro.

Recebido em outubro de 2003 Aprovado em fevereiro de 2004 
gulamentos que levaram à criação de um grupo de trabalho específico sobre educação matemática na ANPEd (Igliori).

Miguel e Garnica, por fim, discutem, sob referenciais distintos, a disciplinarização da educação matemática. São, em resumo, quatro olhares e vozes que, ora em fina sintonia, ora em contraponto, surgem fincados no espaço que os autores desejam, com seus discursos, ver consolidado: a educação matemática.

Palavras-chave: educação matemática; pesquisa; disciplinarização

Mathematical education: a brief history, actions adopted and questions on its formation as a discipline

This text was elaborated in autonomous topics in order to discuss the configuration of mathematical education as an area of research and, in a historical panorama, explains and analyses how the efforts for its consolidation in Brazil have been effectively implemented. Starting from a presentation of some elements related to the emergence and organisation of research in mathematical education within an international perspective (D'Ambrósio), it goes on to sketch in the motivations and difficulties which led to the creation of a specific working group in mathematical education within ANPEd (Igliori). Finally, Miguel and Garnica discuss the implementation of mathematical education as a discipline from different theoretical perspectives. There are, then, four different views and voices, at times finely tuned and, at others, discordant which arise rooted in that space which the authors with their discourses, desire to see consolidatedmathematical education.

Key-words: mathematical education; research; formation as a discipline

Saddo Ag Almouloud e outras

A geometria no ensino fundamental: reflexões sobre uma experiência de formação envolvendo professores e alunos

Discute os principais resultados de um projeto de pesquisa que teve como objetivo investigar problemas relativos ao ensino e à aprendizagem da Geometria, enfrentados por professores da rede pública estadual de ensino, bem como por seus alunos de $5^{\mathrm{a}}$ a $8^{\mathrm{a}}$ séries. Analisa essencialmente procedimentos metodológicos, fundamentos teóricos e principais resultados, focalizando a origem dos problemas relacionados com o ensino e a aprendizagem da Geometria, as estratégias montadas para enfrentar uma parte desses problemas e as mudanças de concepções e práticas de professores.

Palavras-chave: ensino e aprendizagem; geometria; formação de professores; mudança de práticas pedagógicas

The geometry in primary education: reflections on a training experience involving teachers and school children

In this text we present the main results of a research project whose aim was to investigate teaching and learning problems in Geometry, faced by public school teachers and their pupils from $5^{\text {th }}$ to $8^{\text {th }}$ grade. We intend to concentrate our discussion on methodological procedures, theoretical concepts and main results, focusing our analysis on three aspects: first, the origin of problems related to the teaching and learning of Geometry; second, the courses of action adopted to confront some of these problems; and third, changes in teachers' concepts and practices.

Key-words: teaching and learning; geometry; teacher development; changes in pedagogical practices

Maria Cecilia de Castello Branco Fantinato
A construção de saberes matemáticos entre jovens e adultos do Morro de São Carlos

O texto procura compreender as relações entre os conhecimentos matemáticos construídos por jovens e adultos trabalhadores na vida cotidiana e os conhecimentos matemáticos escolares. Para tanto, foi desenvolvida uma pesquisa etnográfica no Morro de São Carlos, Rio de Janeiro, acompanhando a rotina local de um curso de educação de jovens e adultos, assim como aspectos da vida diária dos alunos e da vida comunitária na favela. Os resultados indicaram uma estreita associação entre o uso de habilidades matemáticas no cotidiano com a necessidade de garantir formas de sobrevivência, assim como a importância de fatores afetivoemocionais como impulsionadores de raciocínio matemático. $\mathrm{O}$ mundo da escola e o mundo da vida cotidiana apareceram como separados, assim como os conhecimentos matemáticos pertencentes a um ou outro contexto. Palavras-chave: etnomatemática; educação matemática de jovens e adultos; representações quantitativas e espaciais

The construction of mathematical knowledge by young people and adults from Morro de São Carlos This study aimed to understand relationships between the everyday mathematical knowledge constructed by working-class youth and adults and the school mathematical knowledge that they confront when they return to school for basic education. For this study, an ethnographic research methodology was developed in a poor neighbourhood of the city of Rio de Janeiro, Morro de São Carlos, monitoring routines of a local course for adult education, as well as aspects of the daily life of the students and their community. Results showed a strong association between the use of mathematical skills in daily life and survival strategies to satisfy basic needs. Emotional factors appeared to stimulate some of the subjects' mathematical strategies. For 
the adults of our study, school world and daily life world were represented as separated, as well as the mathematical knowledge generated in each of these contexts.

Key-words: ethnomathematics; adult basic education; quantitative and spatial representations

Maria Isabel Brandão de Souza Mendes e Terezinha Petrucia da Nóbrega

\section{Corpo, natureza e cultura:} contribuições para a educação Ao se discutir a construção teórica da relação entre os conceitos de estes conceitos, busca-se apontar possíveis contribuições para a educação. Ao conceber que estes conceitos se interpenetram através de uma lógica recursiva, que o corpo é uma construção biocultural, um corpo vivo, e ao compreender que os opostos, em vez de se isolarem, se complementam, se poderá reconhecer tanto a autonomia do corpo quanto a sua dependência com o meio, a cultura e a sociedade em que vive. Desse modo, a educação, ao perceber que não é possível ir em busca de um corpo isento de história, e ao reconhecer a responsabilidade que possui ao colaborar com a reescrita dessa história, tem o desafio de permitir desabrochar as subjetividades, abrindo espaços que possibilitem aflorar um ser que, ao modificar-se constantemente, provoca mudanças no ambiente, na sociedade, na cultura.

Palavras-chave: corpo; educação; epistemologia; natureza; cultura

\section{Body, nature and culture:} contributions for education In discussing the theoretical construction of the relation between the concepts of body, nature and culture, this article seeks to point to possible contributions for education. By conceiving that body, nature and culture are interwoven by a recursive logic, that the body is a biocultural construction, a living body, and by understanding that the opposites, instead of isolating themselves, complement each other, it should be possible to recognise both the autonomy of the body and its dependence on the environment, culture and the society in which it resides. In this way, by perceiving that it is not possible to look for a body exempt from history, and by recognising the responsibility which it has in collaborating with a rewriting of that history, education faces the challenge of permitting subjectivities to blossom, opening spaces which will allow a being to bloom who, by constant modification, provokes changes in the environment, society and culture.

Key-words: body; education, epistemology; nature; culture

Sonia Maria Rummert

Programa Integração: avanços e contradições de uma proposta de educação formulada pelos trabalhadores

Este artigo analisa o Programa Integração, desenvolvido pela Central Única dos Trabalhadores (CUT), no âmbito do Programa de Qualificação Profissional (PNQP). Aborda especificamente o caso do Programa Integração do Sindicato dos Trabalhadores em Telecomunicações do Rio de Janeiro, focalizando a problemática das telecomunicações no Brasil e suas repercussões junto aos trabalhadores e às suas entidades representativas. São também abordadas as contradições inerentes à opção da CUT pelo papel de executora de uma política de educação dos trabalhadores, materializada no Programa Nacional de Qualificação Profissional (PLANFOR), implementada pelo Estado, sob a hegemonia do ideário neoliberal. São analisados também os avanços e os limites das contribuições teórico-metodológicas do Programa Integração à educação de jovens e adultos trabalhadores, dando especial relevo às suas potencialidades.

Palavras-chave: educação básica e profissional de jovens e adultos trabalhadores; movimento sindical e educação; fundamentos teórico-metodológicos da educação de jovens e adultos trabalhadores.

Integration Programme: advances and contradictions in an educational proposal formulated by workers

The text analyses the Integration Programme, developed by the Workers Central Trade Union Organisation (CUT), within the context of the Programme of Professional Qualification (PNQR). It deals specifically with the way in which this programme was implemented by the Telecommunication Workers' Trade Union in Rio de Janeiro, focusing on the problem of telecommunications in Brazil and its repercussions on workers and on their representative entities. The contradictions inherent in CUT's option for the role of executor of a policy of workers' education, embodied in the National Programme of Professional Qualification (PLANFOR), implemented by the State under the hegemony of neoliberal inspiration are also discussed. The advances and limitations of the theoretical-methodological contributions of the Integration Programme to the education of adult and young workers are also dealt with, giving special emphasis to their potential.

Key-words: primary and professional education for young and adult workers; trade union movement and education; theoretical-methodological foundations of education for young and adult workers

Mauricio Rocha

Paradoxo da formação: servidão voluntária e liberação 